\title{
Correction to: Photosystem I-LHCII megacomplexes respond to high light and aging in plants
}

\author{
Eliezer M. Schwarz ${ }^{1}$ - Stephanie Tietz ${ }^{1}$ John E. Froehlich ${ }^{1,2}$
}

Published online: 5 February 2018

๑) Springer Science+Business Media B.V., part of Springer Nature 2018

\section{Correction to: Photosynth Res}

https://doi.org/10.1007/s11120-017-0447-y

The funding statement in the last sentence of the Acknowledgements section in the original publication is incorrect. The corrected Acknowledgements section is printed below.

Acknowledgements We would like to thank Dr. Daniel Ducat and Dr. Peter Neofotis for thoughtful critique of the manuscript. Thanks to Dr. Gary Blanchard for access to the laser lab and generous help with TCSP analysis. This work was supported by a grant from the Chemical Sciences, Geosciences, and Biosciences Division, Office of Basic Energy Sciences, Office of Sciences, U.S. Department of Energy (DE-FG02-91ER20021).

The original article can be found online at https://doi.org/10.1007/ s11120-017-0447-y.

Eliezer M. Schwarz

Schwa337@msu.edu

1 Department of Energy Plant Research Laboratory, Michigan State University, East Lansing, MI 48824, USA

2 Department of Biochemistry and Molecular Biology, Michigan State University, East Lansing, MI 48824, USA 